\title{
Analysis of the Pressure Rise in a Partially Filled Liquid Tank in Microgravity with low Wall Heat Flux and Simultaneous Boiling and Condensation
}

\author{
Mohammad M. Hasan* and R. Balasubramaniam ${ }^{\dagger}$ \\ NASA Glenn Research Center, Cleveland, Ohio 44135
}

\begin{abstract}
Experiments performed with Freon 113 in the space shuttle have shown that in a process of very slow heating, high liquid superheats can be sustained for a long period in microgravity. In a closed system explosive vaporization of superheated liquid resulted in pressure spikes of varying magnitudes. In this paper, we analyze the pressure rise in a partially filled closed tank in which a large vapor bubble (i.e., ullage) is initially present, and the liquid is subjected to a low wall heat flux. The liquid layer adjacent to the wall becomes superheated until the temperature for nucleation of the bubbles (or the incipience of boiling) is achieved. In the absence of the gravity-induced convection large quantities of superheated liquid can accumulate over time near the heated surface. Once the incipience temperature is attained, explosive boiling occurs and the vapor bubbles that are produced on the heater surface tend to quickly raise the tank pressure. The liquid-vapor saturation temperature increases as well. These two effects tend to induce condensation of the large ullage bubble that is initially present, and tends to mitigate the tank pressure rise. As a result, the tank pressure is predicted to rise sharply, attain a maximum, and subsequently decay slowly. The predicted pressure rise is compared with experimental results obtained in the microgravity environments of the space shuttle for Freon 113. The analysis is applicable, in general to heating of liquid in closed containers in microgravity and to cryogenic fuel tanks, in particular where small heat leaks into the tank are unavoidable.
\end{abstract}

\section{Nomenclature}

$f \quad$ function defined in Eq (6)

$g \quad$ function defined in $\mathrm{Eq}(20)$

$G \quad$ Rate of change of heater temperature with time, $G=\Delta T_{\text {incp }} / t_{0}, \mathrm{~K} / \mathrm{s}$

$k \quad$ Liquid thermal conductivity, $\mathrm{W} /(\mathrm{m} \mathrm{K})$

$\hat{L} \quad$ Latent heat of vaporization, $\mathrm{J} / \mathrm{kg}$

$N \quad$ Number of vapor bubbles nucleated

$P \quad$ Tank pressure, $\mathrm{Pa}$

$P_{\infty} \quad$ Initial tank pressure, $\mathrm{Pa}$

$r \quad$ Radial coordinate, $\mathrm{m}$

$R_{g} \quad$ Gas constant, $\mathrm{J} /(\mathrm{kg} \mathrm{K})$

$R_{1} \quad$ Radius of expanding vapor bubble, $\mathrm{m}$

$R_{10} \quad$ Initial radius of expanding bubble, $\mathrm{m}$

$R_{2} \quad$ Radius of ullage bubble, $\mathrm{m}$

$R_{20} \quad$ Initial radius of ullage bubble, $\mathrm{m}$

$t \quad$ Time, $\mathrm{s}$

$t_{0} \quad$ Time at which bubbles nucleate after heater is turned on, $\mathrm{s}$

T Temperature, $\mathrm{K}$

\footnotetext{
*Senior Aerospace Engineer.

${ }^{\dagger}$ Research Associate Professor, National Center for Space Exploration Research Center, NASA GRC/ Case Western Reserve University, Cleveland, Ohio.
} 


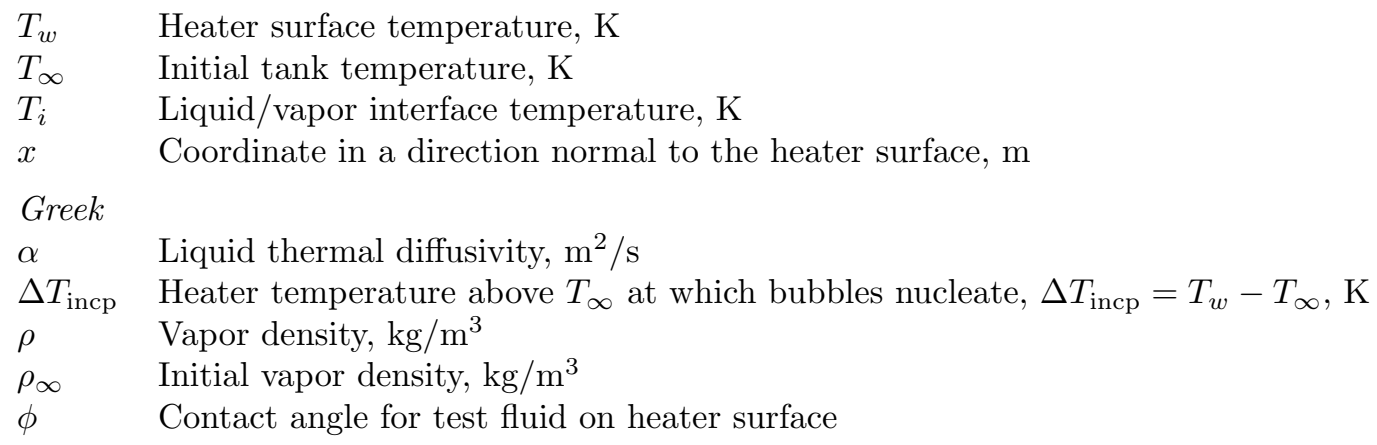

\section{Introduction}

Heating of liquid in microgravity environments may cause problems normally not encountered in the Earth's gravitational environment. Experiments performed with Freon 113 in the space shuttle ${ }^{1,2}$ have shown that in a process of very slow heating high liquid superheats can be attained and sustained for a long period in microgravity. The experimental results show that explosive vaporization of superheated liquid resulted in pressure spikes of varying magnitudes in the closed system. The pool boiling experiment of Merte and $\mathrm{Lee}^{3}$ performed in the space shuttle also reported relatively high liquid superheats and the onset of boiling at low level of heat flux not otherwise possible in Earth's gravitational field. The authors ${ }^{3}$ described this phenomenon as the quasi-homogeneous nucleation in microgravity at low heat flux. The phenomenon observed in microgravity is distinctly different from the explosive vaporization of liquids under rapid heating conditions in Earth's gravity e.g., as cited in references $[4,5]$.

High liquid superheat at very low heat flux is of special significance to the storage of cryogenic liquids in microgravity. In microgravity environments liquid-vapor configurations, principally determined by the surface tension force and the contact angle, present unique thermal problems for the storage of cryogens. While the vapor phase usually occupies the upper portion of any vessel in normal gravity, in microgravity, depending on the vessel geometry and the liquid fill fraction, the vapor phase is more often surrounded by the liquid phase. Heat transfer occurs from the tank wall to the liquid and because natural convective currents are absent in microgravity, the entire liquid or a significant portion of it becomes superheated even at very low heat fluxes. Cryogenic liquids wet solid surfaces because the contact angle is nearly zero and contain little dissolved gases. Therefore, the cryogenic liquids are readily superheated and can attain very high superheat approaching the spinodal temperature before nucleation. ${ }^{6}$ Once the nucleation occurs the explosive vaporization may result in pressure spikes that may cause problems for the cryogenic liquid storage systems in-space.

In this paper, we analyze the pressure rise in a partially filled closed tank in which a large vapor bubble is initially present, and the liquid is subjected to a low wall heat flux. The liquid layer adjacent to the wall becomes superheated until the temperature for nucleation of the bubbles (or the incipience of boiling) is achieved. In the absence of the gravity-induced convection large quantities of superheated liquid can accumulate over time near the heated surface. Once the incipience temperature is attained, explosive boiling occurs and the vapor bubbles that are produced tend to quickly raise the tank pressure. We compare the results of our analysis with the experiments reported in references $[1,2]$.

\section{The Experiment}

In this paper we describe the salient features of the "Tank Pressure Control Experiment: Thermal Phenomena in Microgravity (TPCE) reported in ref[1]. The schematic of the experimental system of TPCE is shown in Figure 1. Figure 2 is a photograph of the test tank showing heaters and other accessories installed. It consists of a 0.254 -m-diameter cylindrical tank with hemispherical domes. The tank volume is $0.0137 \mathrm{~m}^{3}$. The tank is filled with Freon 113 to about 83 percent by volume. Two heaters, designated as heater A and heater $\mathrm{B}$, are immersed in the fluid. Heater $\mathrm{A}$ is located within $0.005 \mathrm{~m}$ of the end of the tank wall and heater $\mathrm{B}$ is off the tank major axis and approximately $0.025 \mathrm{~m}$ away from the tank wall. The heaters are constructed of an etched-foil element encased in silicon rubber insulation and sandwiched between two 304L stainless steel plates. The outside dimensions of the heater assembly are $0.1046 \mathrm{~m}$ by $0.0742 \mathrm{~m}$. The total 
surface area (both sides of the heater) is $0.0155 \mathrm{~m}^{2}$. Both heaters are the same size, except that heater A is bent to a 0.121-m radius to follow the curvature of the tank wall. The heater assembly is welded to a standoff tube that supports the assembly and contains the electrical leads. The total mass of each heater, excluding the standoff tube and thermistor, is $0.214 \mathrm{~kg}$, and the thermal capacitance is estimated to be 0.10 $\mathrm{kJ} / \mathrm{deg} \mathrm{C}$. Power is supplied to the heater by a battery pack consisting of $96 \mathrm{~F}$-size alkaline cells.

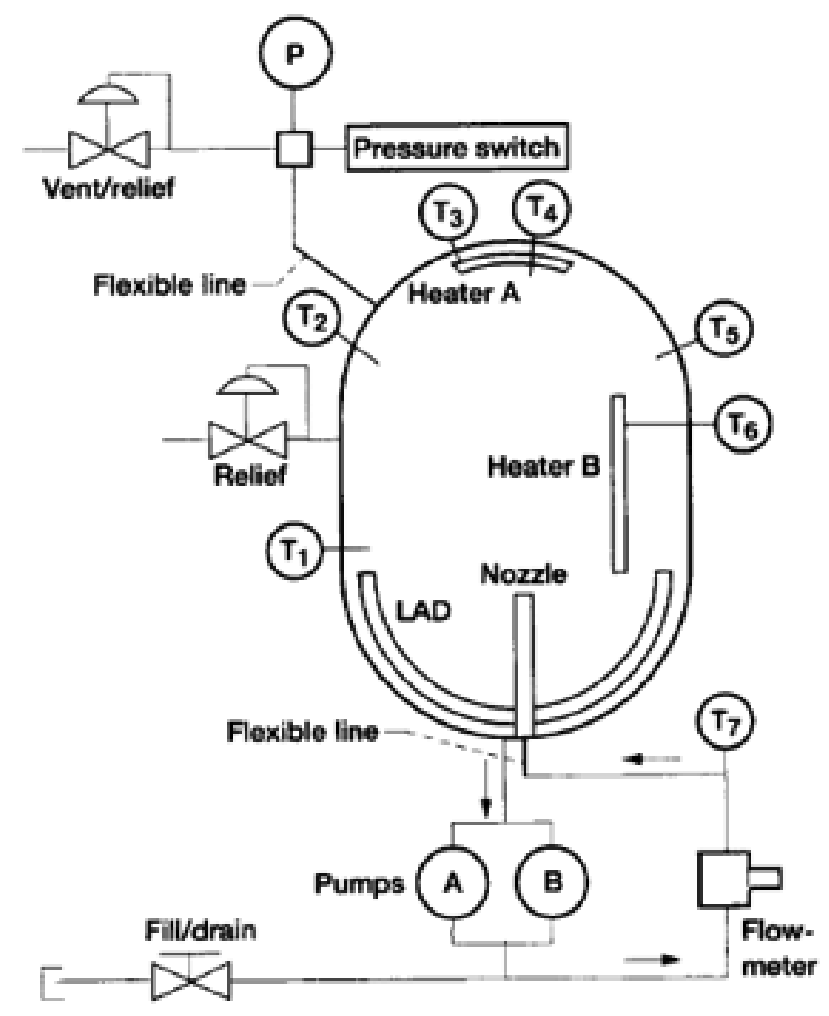

Figure 1. Schematic of experimental system

The primary measurements during a test include tank pressure, heater power, heater surface temperature, liquid temperatures at various locations. The temperature probes shown in Figure 1 are thermistors encapsulated in stainless steel sheaths. Thermistors T3 and T6 measure the surface temperature of heaters $\mathrm{A}$ and $\mathrm{B}$, respectively. Other thermistors measure liquid temperature at various locations in the tank. The apparatus and the range of accuracy of measuring devices are described by Bentz. ${ }^{2}$

Figure 3, a still photograph taken from the flight videotape, shows an actual liquid-vapor configuration during a typical test run. The tank wall is entirely wetted by the liquid. The nearly spherical vapor bubble (also referred to as "an ullage bubble") surrounded by liquid represents 17-percent vapor volume. The location of the ullage bubble could not be controlled during a test. However, for most of the test runs during tail-first orbiter attitude the ullage bubble remained quiescent and located near heater A. The experiment in the space shuttle was performed under steady-state thermal conditions. At the start of the heating the bulk liquid temperature was generally within $1 \mathrm{deg} \mathrm{C}$ of the saturation temperature at the tank pressure. The initial tank pressure during the test runs ranged from 44 to $51 \mathrm{kPa}$. The heater power was constant during each test. The heater wall heat flux during the entire test runs ranged from 0.86 to $1.1 \mathrm{~kW} / \mathrm{m}^{2}$. Experimental data show that the incipient boiling wall superheat was affected by the location and movement of the ullage bubble. The incipient boiling wall superheat $\left(\Delta T_{\text {incp }}=T_{w}-T_{\infty}\right)$ is defined as the difference between the heater surface temperature and the saturation temperature corresponding to the tank pressure at the instant of boiling inception. The surface temperatures of heaters A and B were measured by thermistors T3 and T6, respectively. The spatial variation of the heater surface temperature was not measured.

Figures 4(a) to (d) are still photographs taken from the flight videotape for run 13. The sequence of the photographs clearly shows the occurrence of explosive boiling from heater A and the subsequent liquid motion. When heater A was turned on (Figure 4(a)) the ullage bubble was approximately $0.04 \mathrm{~m}$ away 


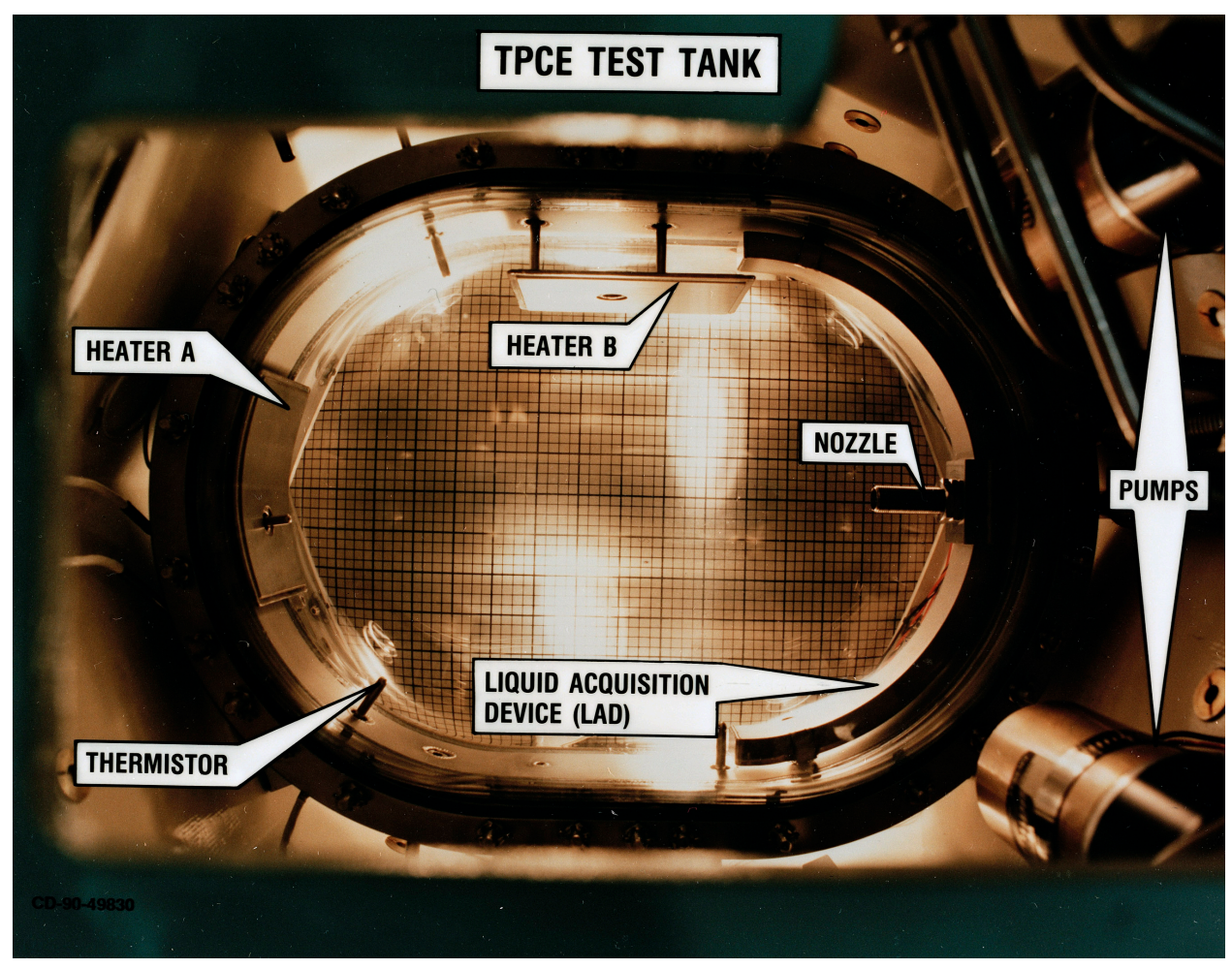

Figure 2. Plexiglass test tank showing heaters and other accessories.

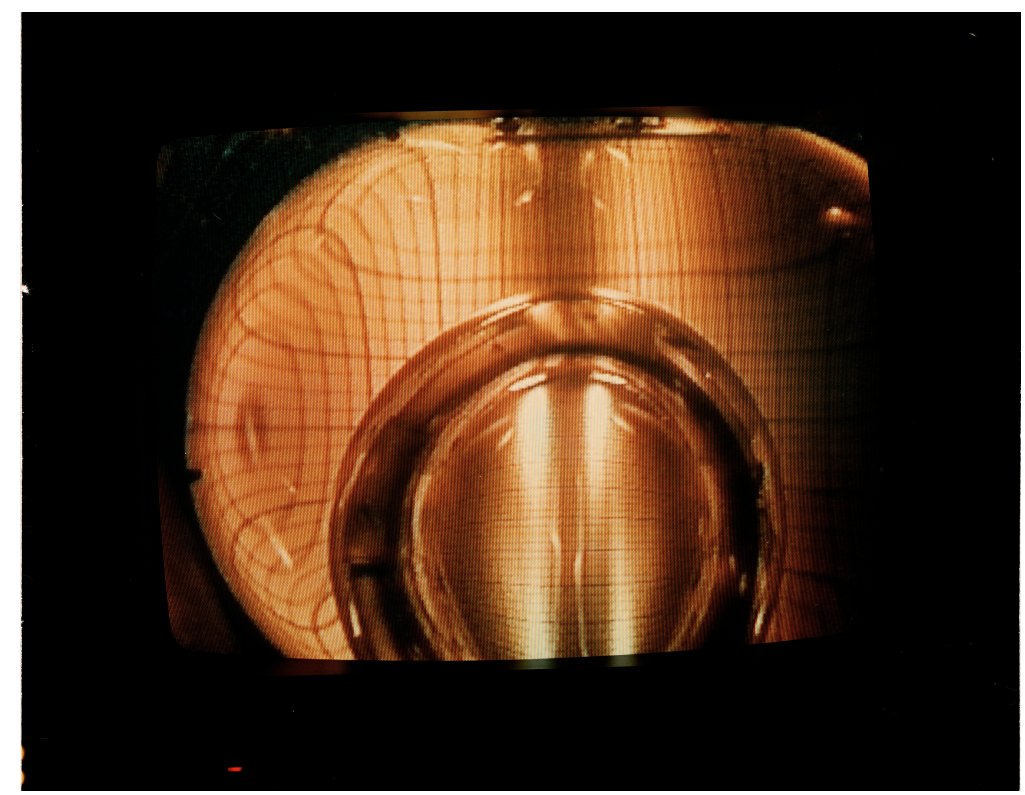

Figure 3. Actual liquid-vapor configuration during flight experiment 
from heater A. After 9 minutes and 46 seconds of heating (Figure 4(b)) the ullage bubble location remained practically unchanged. Figure 5 shows the heater wall temperature and the tank pressure as functions of time for run 13. During 9 min and $46 \mathrm{~s}$ of heating the heater surface temperature (measured by thermistor T3) increased from $26.7 \mathrm{C}$ to $46.2 \mathrm{C}$. The tank pressure during this time changed only slightly, from 50.3 to $50.7 \mathrm{kPa}$. The tank pressure after the explosive vaporization reached a value of $70 \mathrm{kPa}$.

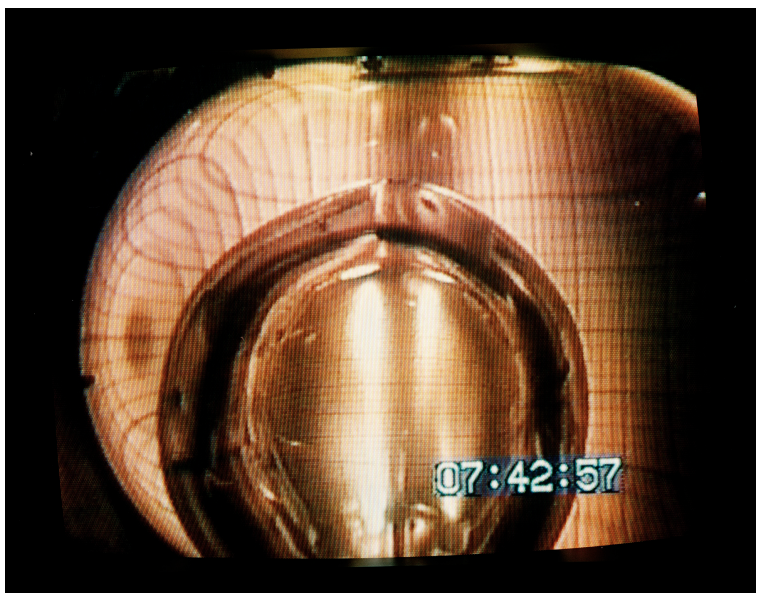

(a)

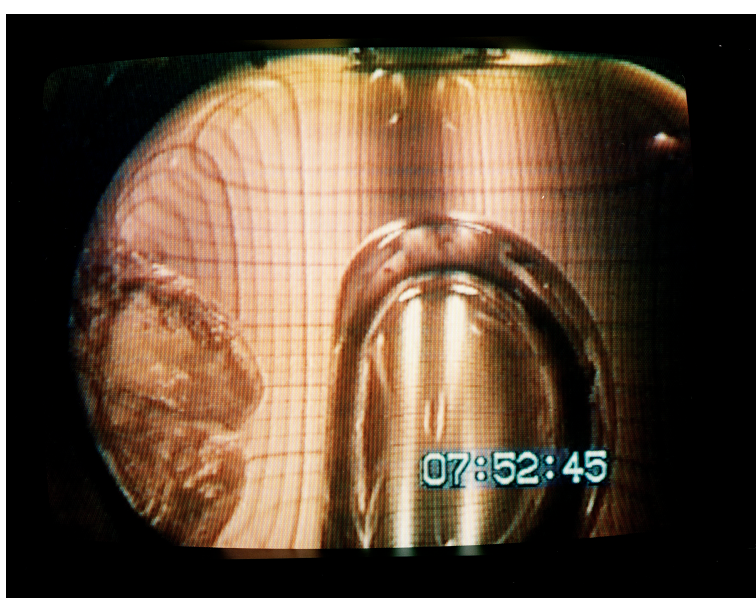

(c)

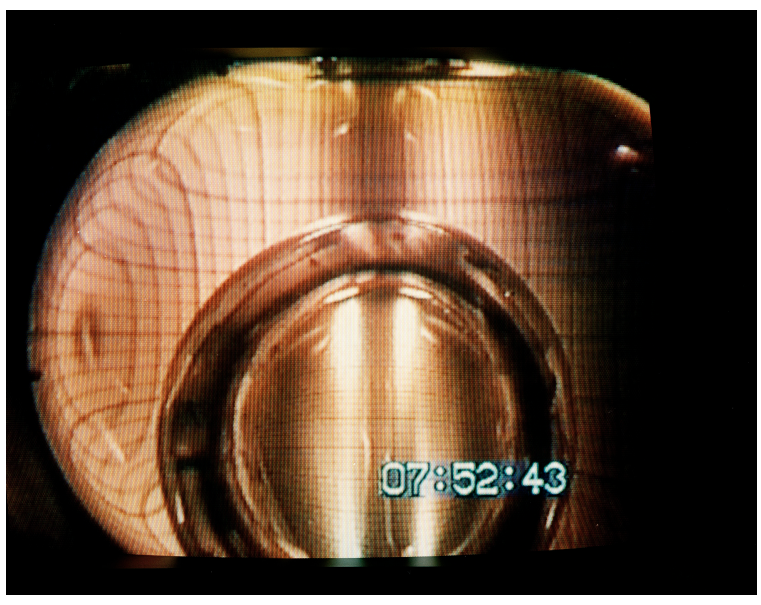

(b)

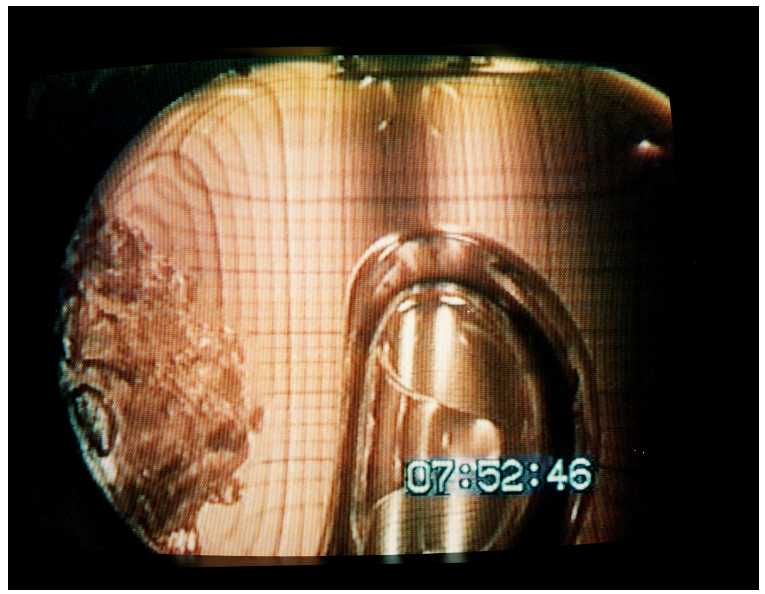

(d)

Figure 4. Explosive boiling from heater A and subsequent events (run 13). (a) Initial liquid-vapor configuration: elapsed heating time, 0 s. (b) Liquid-vapor configuration: elapsed heating time, 9 min and 46 s. (c) Initiation of explosive boiling: elapsed heating time, $9 \mathrm{~min}$ and $48 \mathrm{~s}$; wall superheat, $17.9 \mathrm{deg}$ C. (d) Growth of vapor mass and violent bulk liquid motion: elapsed heating time, 9 min and $49 \mathrm{~s}$.

\section{Model Description}

Consider the liquid in the tank that is assumed to be initially at the saturation temperature at the prevailing pressure. The liquid is in thermodynamic equilibrium with the ullage bubble. Our goal is to predict the pressure in the tank and the size of the ullage bubble, as a function of time, when the liquid is slowly heated by a submerged heater and the liquid near the heater surface vaporizes.

The time period for liquid response can be divided into two intervals, namely before and after vapor bubbles nucleate on the heater surface. As mentioned before, the liquid adjacent to the heater is superheated until the incipience of boiling. Nucleation of vapor bubbles on the heater surface typically occurs by heterogeneous nucleation, due to dissolved gas or trapped air bubbles in crevices on the surface. For cryogenic liquids, such impurities may not be present, and the liquid superheat may approach the spinodal 


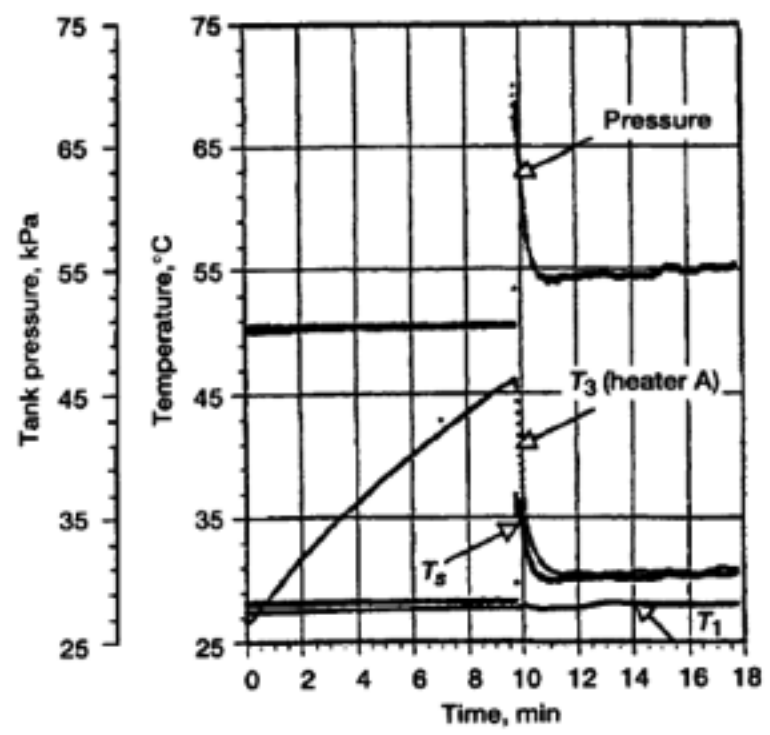

Figure 5. Heater $\mathrm{A}$ and liquid temperatures and tank pressure as functions of time

temperature for homogeneous nucleation. In our model we will assume heterogeneous nucleation. At the onset of nucleation, the surface temperature $T_{w}$ must be greater than $T_{\infty}+\Delta T_{\text {incp }}$ where $T_{\infty}$ is the initial tank temperature at which the liquid and vapor are saturated and coexist, $\Delta T_{\text {incp }}$ is the superheat for incipience of boiling (i.e., bubble nucleation), and is assumed to be a known quantity in the model that may be different for each experimental run.

The theory we present is organized as follows. We consider the liquid heat-up phase first, followed by the nucleation and growth of vapor bubbles on the heater surface. After that we describe how we model the heat transfer near the ullage bubble. Finally, we pose the problem for the determination of the tank pressure taking into account the heat transfer near the growing vapor bubbles and the shrinking ullage bubble simultaneously.

\section{Liquid heat-up phase}

While the heat input rate to the heater is constant, its thermal mass is typically non-negligible. The thermal conductivity of the heater materials is also quite large compared to that of the liquid. Under these conditions we have found that a linear variation of heater surface temperature with time is a good approximation (see for example Figure 5 for $0<t<10 \mathrm{~min}$ ). We will impose a linearly varying wall temperature with time in our model. Assuming that heat transfer occurs from the heater to the liquid by conduction, a one-dimensional model for the temperature distribution in the liquid adjacent to the heater prior to vapor formation can be described as follows.

$$
\frac{\partial T}{\partial t}=\alpha \frac{\partial^{2} T}{\partial x^{2}}
$$

with the initial condition

$$
T=T_{\infty} \text { at } t=0
$$

and boundary conditions

$$
\begin{gathered}
T=T_{\infty}+G t \text { at } x=0 \\
T \rightarrow T_{\infty} \text { as } x \rightarrow \infty
\end{gathered}
$$

The solution for the liquid temperature is

$$
T=T_{\infty}+G\left(t+\frac{x^{2}}{2 \alpha}\right) \operatorname{erfc} \frac{x}{2 \sqrt{\alpha t}}-\frac{G x \sqrt{t}}{\sqrt{\pi \alpha}} \exp \left(-\frac{x^{2}}{4 \alpha t}\right)
$$


During the liquid heat-up phase, the ullage bubble is assumed to be unaffected. This is valid when the bubble is sufficiently far away from the heater. There likely will be a small pressure increase in the tank due to thermal expansion of the liquid. In our model we consider the liquid to be incompressible and neglect its thermal expansion. Thus the tank pressure will increase only when vapor bubbles are produced.

\section{Vapor bubble nucleation and growth}

Vapor bubbles will nucleate on the heater surface when the surface temperature $T(0, t)=T_{\infty}+\Delta T_{\text {incp }}$. Thus $\Delta T_{\text {incp }}=G t_{0}$, where $t_{0}$ is the time when vapor bubbles first start to appear. Experimental measurements will be used to provide $t_{0}$ as an input to the model. The temperature distribution in the superheated liquid at the incipience of boiling on the heater surface is

$$
T\left(x, t_{0}\right)=T_{\infty}+G\left(t_{0}+\frac{x^{2}}{2 \alpha}\right) \operatorname{erfc} \frac{x}{2 \sqrt{\alpha t_{0}}}-\frac{G x \sqrt{t_{0}}}{\sqrt{\pi \alpha}} \exp \left(-\frac{x^{2}}{4 \alpha t_{0}}\right) \equiv T_{\infty}+f(x)
$$

Once a vapor bubble is formed, we will assume thermodynamic equilibrium between the bubble and the surrounding liquid. Thus the temperature $T_{i}$ at the liquid/vapor interface of the bubble must equal the saturation temperature corresponding to the tank pressure. At the instant bubbles nucleate $T_{i}=T_{\infty}$, but as the tank pressure changes, $T_{i}$ will change as well. The nucleated bubbles grow by vaporization of the superheated liquid layer, with the energy stored in the liquid providing the latent heat required for conversion of liquid to vapor. We assume that after vaporization starts, the heater is turned off, that is, the amount of energy supplied by the heater during the time that the vapor bubble grows is negligible compared to the energy supplied by the heater in creating the superheated liquid layer.

The heat transfer in the liquid around a single nucleated vapor bubble is assumed to be predominantly by conduction, and we neglect the effects of any convection induced by the bubble growth for simplicity. The model is formulated as follows.

$$
\frac{\partial T}{\partial t}=\alpha \nabla^{2} T
$$

with the initial condition

$$
T=T_{\infty}+f(r) \text { at } t=t_{0}
$$

with $f$ as given in $\mathrm{Eq}(6)$. The boundary conditions are

$$
\begin{gathered}
T=T_{i}(t) \text { at } r=R(t) \\
T \rightarrow T_{\infty} \text { as } r \rightarrow \infty
\end{gathered}
$$

The radius of the bubble and the interface temperature are time-dependent quantities when the bubble expands ( $T_{i}$ is time-dependent because the tank pressure changes with time). We will use a quasi-stationary approach and regard $T_{i}$ and $R$ as constants in the solution of the differential equation given above. The problem posed above is split into two problems:

(i)

$$
\begin{gathered}
\frac{\partial T_{1}}{\partial t}=\alpha \nabla^{2} T_{1} \\
T_{1}=T_{\infty} \text { at } t=t_{0} \\
T_{1}=T_{i} \text { at } r=R ; T_{1} \rightarrow T_{\infty} \text { as } r \rightarrow \infty
\end{gathered}
$$

The solution for $T_{1}$ is

$$
T_{1}=T_{\infty}+\frac{R}{r}\left(T_{i}-T_{\infty}\right) \operatorname{erfc}\left(\frac{r-R}{2 \sqrt{\alpha t}}\right)
$$

The temperature gradient in the liquid at the liquid-vapor interface can be obtained as

$$
\left(\frac{\partial T_{1}}{\partial r}\right)_{r=R}=-\left(T_{i}-T_{\infty}\right)\left(\frac{1}{\sqrt{\pi \alpha t}}+\frac{1}{R}\right)
$$

$$
\frac{\partial T_{2}}{\partial t}=\alpha \nabla^{2} T_{2}
$$




$$
\begin{gathered}
T_{2}=f(r) \text { at } t=t_{0} \\
T_{2}=0 \text { at } r=R ; T_{2} \rightarrow 0 \text { as } r \rightarrow \infty
\end{gathered}
$$

In the solution of the problem for $T_{2}$, we neglect the curvature of the interface and write the Laplacian as $\frac{\partial^{2} T_{2}}{\partial r^{2}}$. The solution for $T_{2}$ is ${ }^{7}$

$$
T_{2}=\frac{1}{2 \sqrt{\pi \alpha t}} \int_{0}^{\infty} f\left(r^{\prime}\right)\left[\exp \left(-\frac{\left(r-r^{\prime}\right)^{2}}{4 \alpha t}\right)-\exp \left(-\frac{\left(r+r^{\prime}\right)^{2}}{4 \alpha t}\right)\right] d r^{\prime}
$$

The temperature gradient in the liquid at $r=R$ is obtained to be

$$
\left(\frac{\partial T_{2}}{\partial r}\right)_{r=R}=\frac{2 G t_{0}}{\sqrt{\pi \alpha t}} \int_{0}^{\infty}\left[\left(1+\frac{2 t}{t_{0}} \xi^{2}\right) \operatorname{erfc}\left(\sqrt{\frac{t}{t_{0}}} \xi\right)-\frac{2}{\sqrt{\pi}} \sqrt{\frac{t}{t_{0}}} \xi \exp \left(-\frac{t}{t_{0}} \xi^{2}\right)\right] \xi \exp \left(-\xi^{2}\right) d \xi \equiv \frac{G t_{0}}{\sqrt{\pi \alpha t}} g(t)
$$

Thus the energy transferred to the vapor from the superheated liquid can be obtained as a function of time by combining results from Eqs (15) and (20), which may then be used in a mass balance equation across the liquid/vapor interface with vaporization to determine the rate of growth of the mass of the vapor bubble. Thus,

$$
\frac{d}{d t}\left(\frac{4}{3} \pi \rho R^{3}\right)=\frac{4 \pi k}{\hat{L}} R^{2}\left(\frac{\partial T}{\partial r}\right)_{r=R}
$$

All these considerations are for a single bubble. In order to predict the tank pressure rise, the total rate of vapor production is required. The number of bubbles that nucleate on the heater surface is difficult to measure or quantify exactly. We use the following correlation developed by Basu, Warrier and Dhir $(2002)^{8}$ to estimate the active nucleation site density on heater surfaces in boiling. These authors used their data as well as those from other investigators in developing the correlation. While it is empirical and there is no assurance that it is valid for all heater surfaces (in particular, what was used in the space experiments in ref[1,2]), we will nevertheless use it as we need to specify the number of bubbles that nucleate in our model to determine the tank pressure rise.

$$
\begin{gathered}
N=0.34(1-\cos \phi) \Delta T_{\text {incp }}^{2}, \quad \Delta T_{\text {incp }}<15^{\circ} C \\
N=3.4 \times 10^{-5}(1-\cos \phi) \Delta T_{\text {incp }}^{5.3}, \quad \Delta T_{\text {incp }}>15^{\circ} \mathrm{C}
\end{gathered}
$$

\section{Ullage bubble}

We now consider the ullage bubble. Prior to the time the heater is turned on, the bubble is in equilibrium with the surrounding liquid. As the tank pressure rises due to vapor production at the heater surface, the ullage bubble will no longer be in equilibrium with the liquid. The liquid/vapor interface temperature will now correspond to the saturation temperature at a larger pressure, and will be higher than the liquid temperature around the bubble. Therefore, energy is transferred from the ullage bubble to the surrounding liquid, and the bubble starts to condense. The time-dependent radius of the condensing bubble is also modeled by a quasi-stationary approach, and Eqs (14) and (21) apply to the ullage bubble as well.

\section{Determination of tank pressure}

We assume that the gas behaves as an ideal gas and that the saturation temperature-pressure relationship is given by Clapeyron's equation. The liquid is incompressible and the total tank volume (the sum of the liquid and vapor volumes) is assumed constant. The thermal conductivity of the liquid and the latent heat of vaporization are assumed to be constants as well.

The equations governing the size of the expanding and condensing bubbles, the tank pressure and the temperature at the liquid/vapor interfaces are described below.

Growing (vapor) bubble(s):

$$
\frac{d}{d t}\left(\rho R_{1}^{3}\right)=\frac{3 k R_{1}^{2}}{\hat{L}}\left[-\left(T_{i}-T_{\infty}\right)\left(\frac{1}{\sqrt{\pi \alpha t}}+\frac{1}{R_{1}}\right)+\frac{1}{\sqrt{t}} g(t)\right]
$$

where $g(t)$ is as defined in Eq (20). 
Shrinking (ullage) bubble:

$$
\frac{d}{d t}\left(\rho R_{2}^{3}\right)=-\frac{3 k R_{2}^{2}}{\hat{L}}\left(T_{i}-T_{\infty}\right)\left(\frac{1}{\sqrt{\pi \alpha t}}+\frac{1}{R_{2}}\right)
$$

Tank volume constraint:

$$
\left(N R_{10}^{3}+R_{20}^{3}\right)\left(1-\frac{\rho_{\infty}}{\rho_{l}}\right)=\left(N R_{1}^{3}+R_{2}^{3}\right)\left(1-\frac{\rho}{\rho_{l}}\right)
$$

This equation represents a constant tank volume. It is derived by equating the sum of the volumes of the liquid and the vapor at any time $t$ to that at time $t=0$ prior to the nucleation of bubbles on the heater surface. The instantaneous liquid volume is not directly tracked in the model. However, the change in the liquid volume from the initial liquid volume can be split into the liquid volume lost due to vaporization on the heater surface, and the liquid volume gained by condensation of the ullage bubble. These are in turn related to the gain in mass of the expanding vapor bubbles on the heater, and the loss in mass of the ullage bubble, respectively, and finally leads to the equation written above.

Ideal gas law:

$$
\rho=\frac{P}{R_{g} T_{i}}
$$

Clayperon's equation:

$$
P=P_{\infty} \exp \left[\frac{\hat{L}}{R_{g} T_{\infty}}\left(1-\frac{T_{\infty}}{T_{i}}\right)\right]
$$

The initial conditions are specified at the time $(\mathrm{t}=0)$ when bubbles nucleate on the heater surface. The initial conditions are

$$
R_{1}(0)=R_{10}, R_{2}(0)=R_{20}, P(0)=P_{\infty}, T_{i}(0)=T_{\infty}, \rho(0)=\rho_{\infty}
$$

Eqs (24) to (29) are five equations for the five unknown time-dependent quantities $R_{1}, R_{2}, P, T_{i}$ and $\rho$. These equations are solved numerically, with the initial radius of the expanding bubbles set to a small non-zero number $\left(R_{10} / R_{20}=10^{-4}\right)$. The initial radius of the ullage bubble is $R_{20}=0.0822 \mathrm{~m}$.

\section{Results and Discussion}

Table 1 displays the measured heater superheat $\left(\Delta T_{\text {incp }}\right)$, the time $\left(t_{0}\right)$ when bubbles nucleate on the heater, the time at which the peak pressure is attained, and the time the heater is turned off, for each test run in the space experiment. These values are used to determine $G=\Delta T_{\mathrm{incp}} / t_{0}$ and $t_{0}$ that is required as input to the model. In the theory, we have assumed that the heater is turned off following bubble nucleation. For experiment runs 2, 3, 4 and 10, this is not a good assumption, as the energy provided by the heater during bubble expansion is more than $10 \%$ of the energy provided for superheating the liquid. The data for

\begin{tabular}{|c|c|c|c|c|c|c|c|c|c|c|}
\hline Heater & Run & Delta T & $\begin{array}{l}\text { Heater turn-on } \\
\text { time (min) } \\
\end{array}$ & $\begin{array}{l}\text { Heater turn- } \\
\text { off time (min) }\end{array}$ & $\begin{array}{c}\text { Bubble } \\
\text { nucleation } \\
\text { time (min) }\end{array}$ & $\begin{array}{l}\text { Peak pressure } \\
\text { time (min) }\end{array}$ & Contact angle & $\begin{array}{c}\text { Nucleation site } \\
\text { density, } \\
\text { quantity/cm^2 }\end{array}$ & $\begin{array}{c}\text { Heater } \\
\text { area, } \mathrm{cm}^{\wedge} 2\end{array}$ & $\begin{array}{c}\text { Number of } \\
\text { nucleated } \\
\text { bubbles }\end{array}$ \\
\hline$A$ & 6 & 5.3 & $\begin{array}{l}0 \\
0\end{array}$ & 9.80 & 2.73 & 2.82 & 10 & 0.145 & 155 & 22.5 \\
\hline A & 7 & 11.1 & 0 & 9.78 & 6.21 & 6.25 & 10 & 0.636 & 155 & 98.6 \\
\hline A & 8 & 10.6 & 0 & 9.78 & 6.47 & 6.51 & 10 & 0.580 & 155 & 90.0 \\
\hline A & 12 & 10.9 & 0 & 17.78 & 8.76 & 8.79 & 10 & 0.614 & 155 & 95.1 \\
\hline A & 17 & 12.6 & 0 & 39.80 & 10.01 & 10.06 & 10 & 0.820 & 155 & 127.1 \\
\hline A & 21 & 2.8 & 0 & 39.78 & 2.22 & 2.38 & 10 & 0.040 & 155 & 6.3 \\
\hline B & 2 & 6.6 & 0 & 9.80 & 2.40 & 2.75 & 10 & 0.225 & 155 & 34.9 \\
\hline B & 3 & 9.6 & 0 & 9.78 & 3.32 & 3.73 & 10 & 0.476 & 155 & 73.8 \\
\hline B & 4 & 6 & 0 & 9.78 & 2.15 & 3.17 & 10 & 0.186 & 155 & 28.8 \\
\hline B & 10 & 6.3 & 0 & 17.80 & 2.45 & 4.47 & 10 & 0.205 & 155 & 31.8 \\
\hline B & 18 & 16.3 & 0 & 39.78 & 7.07 & 7.13 & 10 & 1.373 & 155 & 212.8 \\
\hline A & 13 & 17.9 & 0 & 18.80 & 9.77 & 9.79 & 10 & 2.255 & 155 & 349.6 \\
\hline
\end{tabular}
these runs are given a red symbol in the plots shown below. Table 1 also shows the estimated number of bubbles nucleated on the bubble surface (from Eqs (22) and (23)). The contact angle between the test fluid and the heater surface is taken to be $10^{\circ}$ is these calculations. The thermophysical properties of Freon 113 used in the calculations are given in Table 2.

Table 1: Key experimental measurements and estimated number of nucleated bubbles 


\begin{tabular}{|l|cr|}
\hline Freon 113 gas constant & 43.1 & $\mathrm{~J} /(\mathrm{kg} \mathrm{K})$ \\
Liquid density & 1554.4 & $\mathrm{~kg} / \mathrm{m}^{3}$ \\
Latent heat of vaporization & 150020 & $\mathrm{~J} / \mathrm{kg}$ \\
Liquid specific heat & 960 & $\mathrm{~J} /(\mathrm{kg} \mathrm{K})$ \\
Liquid thermal conductivity & 0.077 & $\mathrm{~W} /(\mathrm{m} \mathrm{K})$ \\
\hline
\end{tabular}

Table 2: Properties of Freon 113

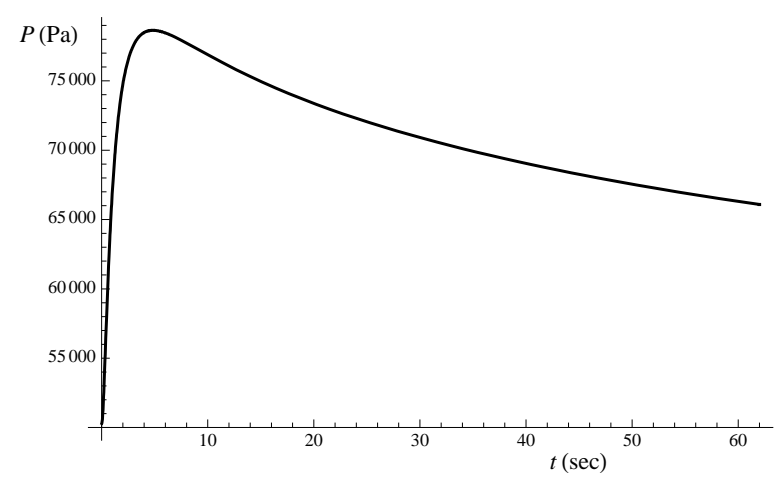

(a)

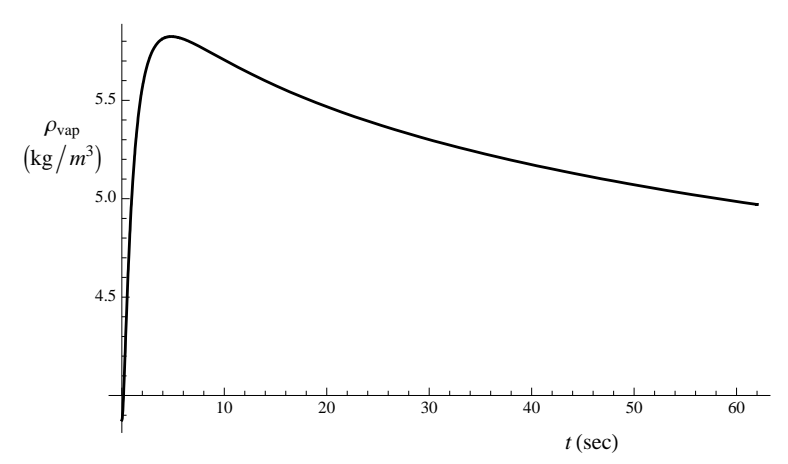

(c)

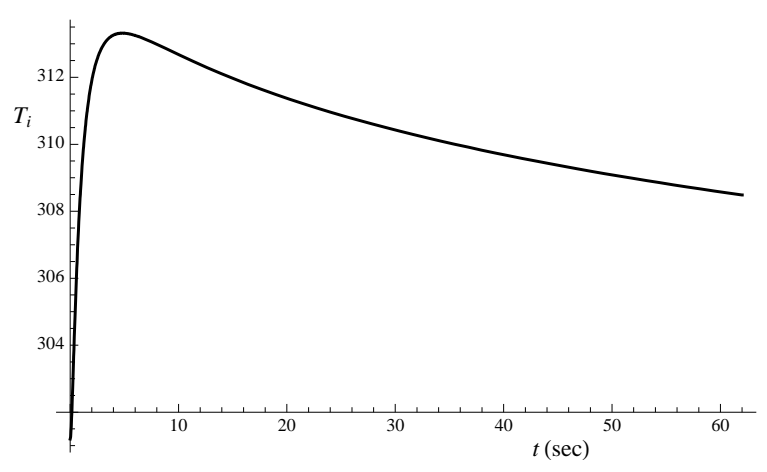

(b)

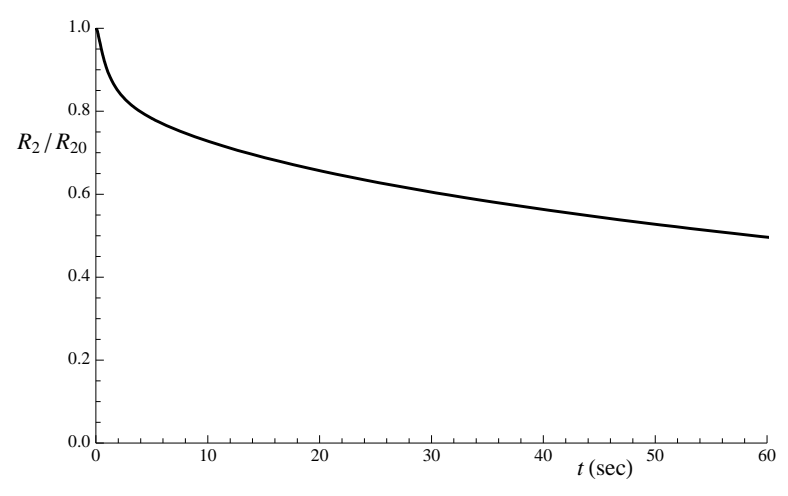

(d)

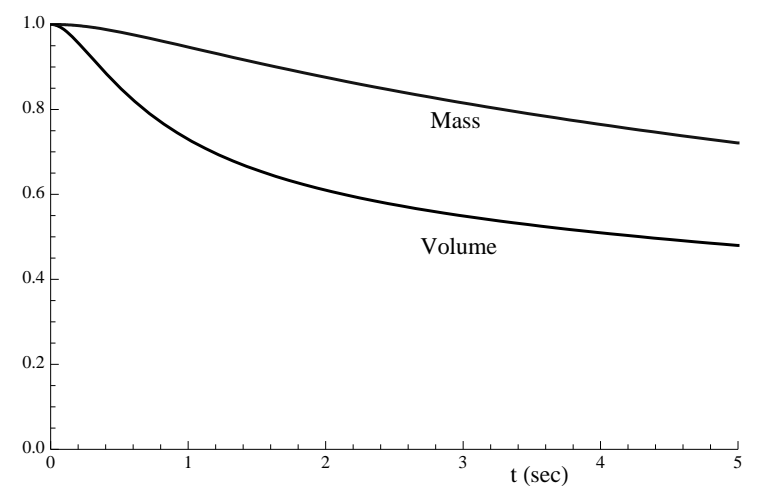

(e)

Figure 6. Model results for experiment run 13 (a) Pressure (b) Liquid-vapor interface temperature (c) Vapor density (d) Radius of ullage bubble relative to its initial radius (e) Mass and volume of the ullage bubble relative to initial values, vs. time. 
The tank pressure, liquid/vapor interface temperature and vapor density, and the size and mass of the ullage bubble (relative to the values at $t=0$ ) as a function of time following bubble nucleation are shown in Figure 6, for experiment run 13. As observed experimentally, the tank pressure rises sharply after the onset of nucleation and quickly attains a peak value. Thereafter, the pressure falls slowly with time, indicating that pressure is relieved presumably by the condensation of the ullage bubble. The radius of the ullage bubble, and its mass and volume relative to initial values, are plotted in Figure 6(d) and 6(e). These results show that the tank pressure and the volume of the ullage bubble show the largest change relative to their initial values, while the density and the interface temperature have more modest changes during the expansion of the vapor. From Figure 6(e) it is evident that the volume of the ullage bubble decreases more rapidly than its mass. Just after $t=0$, the volume change is appreciable while the mass hardly changes, indicating that the the ullage bubble is being compressed (adiabtically) by the tank pressure rise without significant mass loss due to condensation. These trends hold for all the other experiment runs as well.

\begin{tabular}{|c|c|c|c|c|c|c|c|}
\hline \multirow[b]{2}{*}{ Heater } & \multirow[b]{2}{*}{ Run } & \multicolumn{4}{|c|}{ Experimental results } & \multicolumn{2}{|c|}{ Theoretical result } \\
\hline & & $\begin{array}{c}\text { Initial } \\
\text { pressure } \mathrm{Pa}\end{array}$ & $\begin{array}{c}\text { Peak pressure } \\
\text { Pa }\end{array}$ & Pressure ratio & Peak time s & Pressure ratio & Peak time $\mathrm{s}$ \\
\hline$A$ & 6 & 43.5 & 46.9 & 1.08 & 5.4 & 1.028 & 37.64 \\
\hline$A$ & 7 & 44.3 & 58.2 & 1.31 & 2.4 & 1.24 & 11.19 \\
\hline$A$ & 8 & 43 & 61.4 & 1.43 & 2.4 & 1.22 & 11.87 \\
\hline$A$ & 12 & 49.6 & 67.4 & 1.36 & 1.8 & 1.23 & 14.39 \\
\hline A & 17 & 52.9 & 72.7 & 1.37 & 3 & 1.29 & 11.96 \\
\hline$A$ & 21 & 68.4 & 70.6 & 1.03 & 9.6 & 1.0006 & 95.05 \\
\hline B & 2 & 39.6 & 42.7 & 1.08 & 21 & 1.058 & 21.72 \\
\hline B & 3 & 40.4 & 46.9 & 1.16 & 24.6 & 1.16 & 11.59 \\
\hline B & 4 & 41.9 & 46.1 & 1.10 & 61.2 & 1.039 & 26.71 \\
\hline B & 10 & 46.1 & 51.7 & 1.12 & 139.2 & 1.043 & 28.31 \\
\hline$B$ & 18 & 55.7 & 73.8 & 1.32 & 3.6 & 1.43 & 7.24 \\
\hline A & 13 & 50.3 & 70 & 1.39 & 1.2 & 1.56 & 4.83 \\
\hline
\end{tabular}

Table 3: Experimental and theoretical results for the peak pressure ratio and the corresponding time

\begin{tabular}{|c|c|c|c|c|}
\hline $\begin{array}{c}\text { Number of } \\
\text { bubbles }\end{array}$ & 1 & 175 & 350 & 700 \\
\hline $\begin{array}{c}\text { Peak } \\
\text { pressure ratio }\end{array}$ & 1.14 & 1.53 & 1.56 & 1.6 \\
\hline Peak time s & 124.1 & 7.15 & 4.83 & 3.26 \\
\hline
\end{tabular}

Table 4: Sensitivity of the peak pressure ratio and peak time to the number of nucleated bubbles for experiment run 13

Table 3 shows the peak pressure ratio and the time at which the peak pressure occurs in the experiments as well as in the model. The ratio of the measured to the predicted peak tank pressure, and the ratio of the corresponding times are also plotted in Figure 7. From the results in Figure 7a, we see that the magnitude of the peak pressure observed in the experiments is well predicted by the model. The maximum deviation is less than $20 \%$, with the typical deviation being less than $10 \%$. With the numerous assumptions in the model, such an agreement is quite promising. As mentioned before, the red symbols represent test runs where the heater energy provided to the tank following bubble nucleation cannot be considered negligible. However, the peak pressure prediction is not very much in error even for these cases.

The number of bubbles that are nucleated is a key parameter in the model. Since it is difficult to ascertain the accuracy of the number of nucleated bubbles predicted by the correlation we have used, we have varied this number in the model. Table 4 shows the results for the peak pressure ratio and the corresponding time for experiment run 13. We have calculated a limiting case of one bubble, and varied the number of bubbles by a factor of two about the nominal result shown in Table 3 (350 bubbles for run 13). It is seen from these results that the peak pressure ratio nominally predicted has only a weak dependence on the number of bubbles, and the deviation is around $2.6 \%$ when the number of bubbles is doubled.

The time at which the peak pressure occurs, however, is not well predicted by the model. From Table 4 , the time for peak pressure is quite sensitive to the number of bubbles. Also, in Figure 7b, the data where the heater energy input into the tank is appreciable during vapor expansion has a behavior distinctly different from when the energy is negligible. For these latter data points, the experimentally measured peak pressure time is much smaller (around 20\%) than the predicted time. We speculate that this discrepancy is due to convection induced in the tank during the expansion phase of the nucleated vapor bubbles. Note 
that convection has not been included in the model. From Figures 4(c) and 4(d) for run 13, it is clear that the shape of the ullage bubble is different on the side facing the heater, strongly indicating the presence of convection. Also, in Figure 4(d) there is evidence of a jet-like liquid region penetrating the ullage bubble. Convection in the liquid will likely alter the temperature distribution around the growing vapor bubbles as well as the ullage bubble, and would probably tend to increase the temperature gradient in the liquid and the associated heat exchange with the bubbles. We speculate that these effects would hasten the time taken to attain peak pressure in the tank.

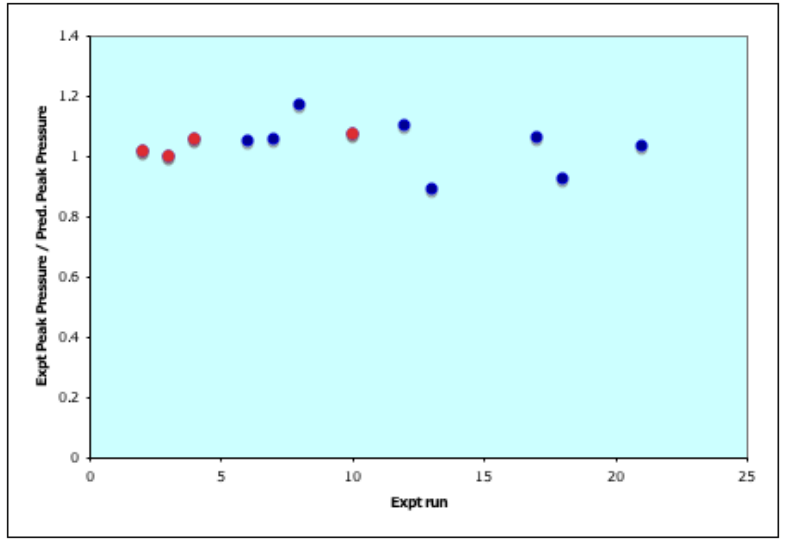

(a)

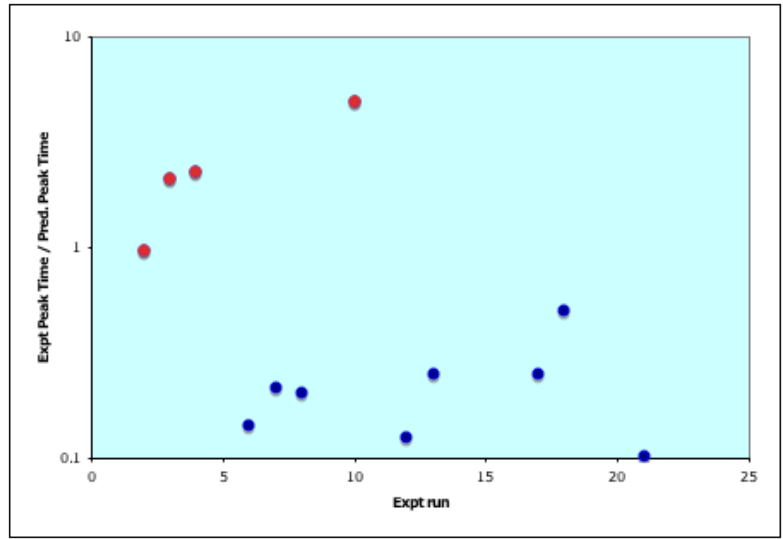

(b)

Figure 7. Ratio of experimental to predicted (a) peak pressure (b) time at which peak pressure occurs, for the various test runs.

\section{Conclusion}

In this paper, we have developed a model for the pressure rise in a closed tank, in which a liquid and its pure vapor in the form of an ullage bubble coexist in microgravity, and the tank is heated by a submerged heater. Before the heater is turned on, the liquid and the vapor are in equilibrium. The model is applicable to predict the pressure rise in cryogenic fuel tanks for space applications where a slow heat leak into the tanks is unavoidable. In the model, the liquid adjacent to the heater is permitted to be superheated beyond the saturation temperature at the prevailing pressure after the heater is turned on, until vapor bubbles nucleate on the heater surface. Thereafter explosive boiling occurs where the nucleated bubbles expand by absorbing heat from the superheated liquid layer. The vapor production causes the tank pressure and the corresponding liquid/vapor saturation temperature to rise, and the ullage bubble will no longer be in equilibrium with the liquid surrounding it. The ullage bubble condenses, tending to relieve the tank pressure rise. Shortly after bubbles nucleate on the heater surface, the model predicts that the tank pressure achieves a maximum rise, followed by a slow decay. Comparison of the model predictions with space shuttle experiments performed using Freon 113 shows that the model correctly predicts the magnitude of the tank pressure rise. The time at which the peak pressure occurs, however, does not compare well, and the experimentally measured times are typically smaller than what is predicted. We speculate that convective effects induced by the bubble expansion, that are not included in the model, are responsible for this discrepancy.

\section{References}

\footnotetext{
${ }^{1}$ Hasan, M. M., Lin, C. S., Knoll, R. H., and Bentz, M. D., 1996 "Tank pressure control experiment: Thermal phenomena in microgravity," NASA TP- 3564, March, 1996

${ }^{2}$ Bentz, M.D., "Tank Pressure Control in Low Gravity by Jet Mixing, NASA Contract NAS3-25363, NASA CR-191012, March 1993.

${ }^{3}$ Merte, H., Jr. and Lee, H.S., "Quasi-Homogeneous Nucleation in Microgravity at Low Heat Flux: Experiment and Theory, ASME Journal of Heat Transfer, Vol. 119, 1997, pp. 305-311.

${ }^{4}$ Skripov, V.P., "Metastable Liquids, John Wiley \& Sons, Inc., New York, 1974.

${ }^{5}$ Reid., R.C., "Superheated Liquids: A laboratory Curiosity and, possibly, an Industrial Curse. Part 2, Industrial Vapor Explosions, Chem. Eng. Educ., 12, 108-111, 1978

${ }^{6}$ Baidakov, V.G., and Skripov, V.P., "Experimental Study of Cryogenic Liquids in the Metastable Superheated State, Experimental Thermal and Fluid Science, Vol.5, pp. 664-678, 1992.

${ }^{7}$ H.S. Carslaw and J.C. Jaeger, "Conduction of Heat in Solids," Oxford University Press, 1959.

${ }^{8}$ Basu, N., Warrier, G.R., and Dhir, V.K., "Onset of Nucleate Boiling and Active Nucleation Site Density During Subcooled Flow Boiling," Journal of Heat Transfer, Vol. 124, pp. 717-728, 2002.
} 